\title{
DIE LEWE VAN DIE CHRISTEN IN DIE WERELD VAN SOSIAAL-POLITIESE SPANNINGE
}

\author{
Dr. K. S. van W. de Vries
}

\section{Proloog}

Ek het besluit om hierdie keer nie geleerd en wetenskaplik te skrywe nie maar om eenvoudig te bly, sodat die eenvoudigste onder ons ook by kan bly. Daarom praat en skryf ek soos ek dink. Dit bring 'n taal en styl na vore wat u miskien sal hinder, maar dit is my eie en ek bied dit nie vir navolging aan nie. U sal ook gou agterkom dat ek nie alles nie, inteendeel, baie min weet en die gebrek aan wysheid en kennis agter baie woorde probeer verberg ook dit is nie navolgingswaardig nie, maar ek voel dat ek dit vandag so moet doen en daarom doen ek dit. En ek skuif my poginkie gerieflik in onder die magistrale na-klanke van die uitnemende sermoen wat $u$ so pas gehoor het.

\section{Spanning tussen twee koninkryke}

In die moderne sosiaal-politiese spanninge het ons ten diepste te doen met die ontplooiing van die koninkryk van God en die koninkryk van die duisternis. Wie dit nie raaksien nie, verstaan die wêreld waarin die gelowige lewe nie. Want die koninkryk van God is in sy bestaan en werking in die hier-en-nou van ons lewe dikwels nie sigbaar nie en 'n ongrypbare grootheid terwyl die koninkryk van die duisternis wel deeglik gesien en gevoel en getas kan word in alles van die hier en nou. En die ryke stuur beide in en deur die vinnige ontwikkeling van hierdie moeë en haas verbygegane eeu na 'n volkomenheid wat vir beide steeds sterker op die horison afgeteken staan.

\section{God regeer}

Die koninkryk van God gaan na sy volkomenheid en kom in sy heerlikheid van die ewige glorie van God, en die ryk van die duisternis gaan na sy volkomenheid en 'n mensgemaakte utopia of in elk geval 'n ,, beter wêreld". Die koninkryk van God groei dinamies, sigbaar-onsigbaar, groter-kleiner, sterker-swakker in 'n praesens-futurum-realiteit, gestuur en geregeer deur die Koning-Priester aan die regterhand van die HERE; in sy beheersing van die universum het Hy skaars tyd om Hom by die stroom te lawe - dan moet Hy weer verder, die kop hoog as Oorwinnaar. Hy rig en bestuur skokgolf op skokgolf wat deur die heelal trek om langs die weg van rampe en oorloë, van dooie liggame van mense en oorwonne grotes van die aarde, verbranding en verwoesting en vernietiging te bring oor die ou, siek wêreld en oor die ryk van die duisternis. En omdat Hy die ryk van God se glorie so laat groei, regeer Hy oor die nasies en maak die HERE die ryk van die duisternis 'n 
voetbank vir sy voete terwyl Hy vernietigend daarop laat skiet deur die duisternis self met veelkoppige-monstermissiele en alles in onstuimige en angsvolle beroering bring want $\mathrm{Hy}$ laat sy ryk groei binne-in en rondom en dwarsdeur die ryk van die duisternis. En ook omdat Hy die ryk van die glorie van God so laat groei en toeneem, maak die HERE sy volk en sy krygsmagte so slaggereed en gespierd soos jongmanne en so heilig en gewillig soos die skittering van doudruppels in die môre; die swaard is nie hul wapentuig nie en mag en geweld nie hulle middels nie. Hulle het die Woord van God, die ,jy moet God liefhê en jou naaste liefhê soos jouself" en die geregtigheid van God - hulle sal met die wil en Woord van God as die absolute normering vir hulle lewe gewillig sterf in die stryd as dit moet, met 'n lied op die lippe van God se glorie wat sy klanke deur die vuurpeleton se blaf en die terroris se geweergeknetter heendra, dwarsdeur die poorte van die dood, om die klanke te paar met die stemme van die oorwinnaarskore wat hooguit nog steeds God se glorie en eer besing.

So groei die boom wat alle bome oorskadu en skuiling bied aan al wat lewe; so groei die koring tussen al die dorings en distels tot die oestyd se jubeltone die draers begelei wat die koring bêre en die werkers wat die onkruid na die vure dra; so dra die een geslag aan die ander oor die aloue belydenis van die Naam bo alle name, Jesus Christus - en dit weerklink by die Vader as die Seun by Hom ook sý volgelinge se naam bely; en dit weerklink in die wêreld tussendeur en teen alle ander belydenis in al oorstem die kommunikasiemedia dit dikwels geheel-en-al; so bly die geloof nog staan en staan daar mense in die geloof terwyl die ongeloof groot en magtig aan die woord is; en so bly die waarheid en liefde en geregtigheid ongeskend en ongeroer in storms van leuen en haat en ongeregtigheid; en so bly God se barmhartigheid in 'n wêreld van vrees en armoede en ellende en verdrukking en bly die Bevelhebber ons oproep: Wees dan barmhartig, soos julle Vader ook barmhartig is; wees dan volmaak, soos julle Vader in die hemele volmaak is - sodat julle kinders kan word van julle Vader wat in die hemele is! En in die geskeurde en gebreekte en sieklike wêreld draai die barmhartige en volmaakte kind van God sy ander wang, seën hy die wat hom vloek, het hy sy vyand lief, bid hy vir die wat hom beledig en vervolg - totdat die Koning kom en $\mathrm{Hy}$ alle haat en leuen en ongeregtigheid tesame met die satan en die ongelowiges en die dood in die hel slinger en die kore van die oorwinnaars losbreek om die ewige eer en heerlikheid aan God te bring.

\section{Die offensief van die Vors van hierdie eeu}

En gelyktydig groei die ryk van die duisternis soos 'n wilde plant wat alles oorwoeker en altyd bly dreig om die groeiende boom van die koninkryk van God met sy grypende takke en slingerende ranke vas te vang en te verwurg. Dit groei en tier welig onder die rustelose sorg van sy koning, die Vors van hierdie eeu, die magtige geestelike wese - mensemoordenaar van die begin af 


\section{In die Skriflig}

en die vader van die leuen. Hy het ook sy leërmagte: duiwels en bose geeste wat vyande van God is en van alles wat goed is; soos moordenaars loer hulle op die kerk - ook op elke lidmaat - om dit met alle mag in die verderf te stort en om alles in die ryk van God deur hulle bedrieëry te verwoes. Maar veral bestaan sy divisies uit die goddelose en verdorwe mense, miljoene en miljoene sterk wat hy aanhits en opsweep om die Christus na die kroon te steek en die bande van God se geestelike en natuurwette te verbreek. Hy laat dit kook en gis in die wêreld van die mense se gedagtes en woorde en dade om die kinders van God geen rus te gun nie en om die kerke te versnipper en te verbreek.

En somtyds mobiliseer hy al sy kragte en magte tot vernietiging en verwoesting en hy durf die Christus op Golgota selfs aan soos 'n draak wat gereed staan om te verslind. En God laat hom ook los - dit is nou in ons tyd - om die volke te verlei en alles van die grote mensheid, wat in getalle op die aarde is soos miere in 'n miershoop so baie, in ' $n$ diep put van moedeloosheid en sieklikheid en frustrasie en onmag en onvrede en angs te gooi. En sy mensemil arde sal, om daaruit uit te kom, die goddeloosheid en vuilheid en ongeregtigheid vermeerder en opbou tot 'n hoë troon, soos nou, waarop die mens van die sonde, die seun van die verderf sal gaan sit om hom te laat aanbid asof hy God is.

En somtyds werk hy stil, geraffineerd, en skiet uit die donker op die hart van die regverdige. Dan gryp hy die wapens van die kinders van God aan; hy misbruik die waarheid van God se Woord, verdraai dit en maak dit half, erger as die leuen, en sien met genoeë terwyl hy hels-skaterlag, hoe sy slagoffers val, ry aan ry, duisende en duisende meer. En hy is op sy gevaarlikste as hy hom voordoen as 'n engel van die lig, 'n boodskapper van Christus wat die manskappe van Christus verkeerde bevele gee en hulle in die ongeluk stort.

\section{„Detente" as strategie}

Daarom soek hy graag wapenstilstand op alle fronte. Die kinders van die mense verbroeder dan met die kinders van God, die mense van die lig met die mense van die duisternis. Die grensdrade word opgerol en vriend en vyand loop deurmekaar gemeng in 'n grys eenheid verder.

En ,detente" staan op sy vaandel! Laat ons in vrede naasbestaan. En ,neutraliteit” versier sy wapenskild: tussenin moet jul wees, nie vir Christus en ook nie teen Hom nie, nie teen satan nie en ook nie vir hom nie, kinders van die skemering en nie van die dag of nag nie. Maar die vermenging en detente en neutraliteit is altyd sleg vir die goeie: dit is Noag se tyd oor en oor, dit is die enkele gifdruppel wat die hele beker wyn 'n doodsbeker maak. Wee hom wie dit drink, wee hom wat detente wil maak met die duisternis en teenoor Christus neutraal wil staan. Dit bring skemer en donker nag en dood; dit trek 'n dik missluier oor die waarheid.

Die waarheid het soek geraak, sê dan die filosowe en die 
teoloë soos Bultman en Kuitert. Christus, ons Profeet, het dit nie aan ons geopenbaar nie, Hy het die sluier van dood en leuen nie stukkend geskeur en lig gebring nie, sê hulle. Nee, jy moet soek en ervaar en met jou mensgedinkte etiek en staatkunde en liefdadigheid na die waarheid toe lewe, wat dit ook al is en waar dit ook al te vinde is. Dan seëvier die leuen - dit word selfs geglo. 'n Leuengees laat die mense glo. En God stuur dié gees. Oor dié nag en leuen roep Christus uit om sy gemeente te troos: Moenie bang wees nie! Ek het die wêreld oorwin! En stry hard om in te gaan. En volhard tot die einde toe. Ek is die waarheid!

\section{Twee ryke en twee strukture}

Ja, mag ek dit in nederigheid ons ,struktuur" noem, ons instituut? Ek is die waarheid! Hy is die Tempel! $\mathrm{Hy}$ is die son van geregtigheid. Ons is die lewende stene. In hierdie "struktuur" gaan hulle in wat stry en gestry het, volhard het tot die einde toe. Dit is hulle wat oorwin en alles beërwe. God sal hulle sy kinders noem, hier en nou en in ewigheid, en hulle sal Hom hulle Vader noem, hier en nou en in ewigheid.

En die ander ,struktuur", as ek dit so mag noem, en ek wil, is die hel. Daarin kom die dood en die leuen en die ryk van die duisternis - én die vreesagtiges! Dis die bangbroeke en slappelinge, die detente-mense en die neutraliste. Gemeng met die ongelowiges en gruwelikes en moordenaars en hoereerders en towenaars en afgodedienaars en al die leuenaars - ál die leuenaars!

So groei die ryke in en deur ons tyd na die volkomenheid van die strukture - Die Tempel, die Lam, die glorie van God én die hel, die ewige dood en donker. En dit moet gou gebeur, sê ons Here en Koning; gou op die afdraand van ons eeu se laaste 22 jaar.

Maar my grootste vrees is dat ons nie meer stry nie. Ek is bang vir die mag en geweld van die ryk van die duisternis, omdat sy huurlinge ons 'n rat voor die oë draai. Want kyk, die argelose Christene en renegaat Christene en die ongeloof probeer saam en deurmekaar 'n struktuur te bou, 'n universum, 'n universiteit. Die lyne daarvan neem al vorm aan, ons kan dit sien, die gebou nader sy voltooiing.

Dis nie 'n Christelike universiteit nie, maar puur wêrelds, humanisties, materialisties. Die beste breinkrag van die wêreld is daar versamel in al die fakulteite van wetenskap en tegniek. En die witgejaste manne en vroue praat met rustige stem en dink en doen met onvoorstelbare kundigheid - hulle bou die komputer vir die wêreldheerser en sy wêreldheerskappy. Uit die fakulteit kom die „Social Gospel” met sy valse gelykheidsleer wat die Protestantisme ondermyn; die cresendo van geleerdheid teen nasionale bewussyn; die valse etiek wat 'n gevoel van diepe skuld en skaamte kweek by elke witman oor sy skuld, gesamentlike en gemeenskaplike skuld - en sommer alle leuenagtigheid wat dit met wetenskaplike presiesheid vir die waarheid opdis met alle kommunikasiemiddels wat reeds in hulle hande is. 


\section{Kerke in die strewe na die utopia}

Die mense, ook die kerke wat Christus nie meer onderskei nie, wil die wêreld 'n leefbaarder plek maak. Die doelpunt is vir die duisternis 'n mensgemaakte utopia, vir dié kerke en baie teoloë die valse koninkryk van God, 'n vrederyk vir hier en nou, sonder diepte of dimensie vir netnou, vir ewig. Vandaar die onrustige geywer van kerkvergaderings en -verenigings en -organisasies, van studie en panele en sentrums en werkgroepe vir die sending en evangelisasie, vir bewaring van die omgewing en vir menseregte - en vir 'n sent hier en 'n gulden of 'n dollar daar vir die vryheidstryders en hongeriges, vir gevange terroriste en slagoffers van verdrukking en diskriminasie en honger en ellende. Die drukte en die praat van die mense om 'n beter wêreld te kry is fantasties, maar hulle harte staan ver en koud. Hulle dink oor die dinge strukturalisties en kan daarom bekritiscer en praat van ,het verderfelijke systeem" van die Afrikaners en dat hulle die sisteem verafsku, te meer omdat die Afrikaanse kerke, so lui dit, hulle hande seënend daaroor hou. Die Here bewaar ons vir 'n geslote oor as mense kritiseer en 'n onbewoë hart as hulle ons vermaan. Want ons skuld is groot en die hand wat uit die boesem kom, siek en melaats. Maar tog het êrens tussen hulle ywer en hulle vermaning die Wet van God verlore gegaan. Die naaste het 'n medemens geword en die liefde ' $n$ vae gevoel van weldadigheid teenoor die mensheid, 'n humanistiese liefde met lengte en breedte sonder hoogte en diepte.

En hoe meer hulle „struktureer" - die hemel weet wat dit beteken, maar dis die modewoord en daarom gebruik ek dit hoe meer maak hulle die persoonlike, innig persoonlike van die liefdesgebod dood. Want die liefdesdaad van die beeld van God moet persoonlik bly, innerlike bewoënheid en gehoorsaamheid van mens tot mens, van mens tot verband en verband tot verband, altyd verantwoord aan God. En jy kan „struktureer" as jy maar net 'n slagspreuk het, liefs uit die Bybel. Met so 'n bespreukte spandoek waai jy soos met 'n towerstaf oor die volke heen, veral die wit Afrikaners, en "presto" - die siektekolle staan uit ten aansien van die hele verontwaardigde wêreld. As daar op sy lapdoek staan: „Human Rights" is jy klaar en finaal veroordeel deur die "one-worlder", die „,new society", die nuwe teologie en etiek, die ",koinonia", die „,new Evangelicals" en elke deklarasie van menseregte wat nog ooit die lig gesien het. Ek sê maar weer, die Here weet hoe skuldig ons is en hoeveel kwaad ons self gemaak het en weer ongedaan moet maak. Maar waarvandaan dan die onwil van Calvyn en De Bres, van Kuyper en J. V. Coetzee om sulke deklarasies te maak of op te stel? Het ons dan tevergeefs geleer of is ons miskien mislei, dat die regte en pligte wat mense het van God afkomstig is, en dat die reg en plig en gesag en mag van die owerheid ook van God af kom en nie deur die onderdaan, met reserwes, aan die owerheid verleen word nie?

Veel erger word dit alles nog as die towerstaf in die hand van ' $n$ sosialis vasgeklem is. Want hy tower sommer alle mense 
gelyk en een, al leer die werklikheid hom die teëdeel. Een en gelyk: eweveel moet elkeen hê, salarisse gelyk vir gelyke werk ure en prestasie en vermoë en produksie tel nie meer nie. En "gelykheid" roep die Christen slagspreuk-skreërs dan. Maar die sosialis se skaduwee, wat altyd groter en sterker is as hy, is die meedoënlose burokrasie wat die owerheid toelaat om sy neus in alle mensverbande in te steek. Vir alles maak hy vorms om ingevul te word. As hulle maklik is, maak hy dit moeilik; as hulle moeilik is maak hy hulle ingewikkeld en van ingewikkeld na onmoontlik - dan is hulle tog perfek! Veral as dit oor welsyn gaan, is die sosialis op sy beste. Aan rade en kommissies en komputers kom geen end nie, maar die slagoffer van die Staatswelsyn se gelykgeskakelde pensioene en versorgingsinstellings is altyd die waaragtige barmhartigheid wat Christus ons leer. Laat ook ons gewaarsku wees! Die botsing kom, sê manne wat weet, tussen die wit jongman wat, as sy vrou beval, sy hand diep in sy sak moet steek tot die nate toe, en die swart jongman wat sy vrou en suigling in puik toestand terug ontvang vir R12 netto.

\section{Etniese meervoudigheid en ,integrated society”}

Maar is dit waar? Is alle mense gelyk? Ek antwoord met 'n Hollandse-Anglisisme wat 'n predikant op 'n sinode te Lunteren gebesig met: Ik neem het niet?! Die ongelykheid is vir my ' $n$ feit en daarom moet daar vir ongelykes ongelyke behandeling wees. Dis nie diskriminasie in die slegte sin nie maar eerlike en noodsaaklike diskriminasie. In die sosiaal-politiese strukture het ons baie woorde gebruik: segregasie en integrasie, apartheid en eiesoortige- en paralelle-ontwikkeling, veelrassige en veelvolkige en plurale samelewing en miskien kom daar meer. Maar van die begin af moes die politiek rekening hou met die rasse en die volke in ons land, dit kon nie anders nie en kan veral vandag nie anders nie. Die staat-strukture wat nou ontstaan begryp ek net ten dele: Transkei en Boputatswana kies van hulle begin af aan vir die veelrassige idee, die „integrated society, multiracial”; Vendaland gaan dit ook doen. Rhodesië is „multiracial” en al die ander Suider-Afrikastate ook, selfs Namibië staan op 'n tweesprong. As ek reg verstaan beteken dit, hoe kan dit anders, swart-meerderheids-regerings. En die term ,meerderheid" word gebruik in rasse-sin, nie etnies nie maar afgelei van die Westminster-demokratiese patroon. Dit gaan ten diepste oor mag, mag in die hande van die swartes en onder hulle in die hande van die sterkste of van die een wat meeste deur die Sowjet of die VSA gehelp word of wat een van hulle welgevallig en dienstig is. Ek sê dit van al die Suider-Afrika-state maar behalwe van Suid-Afrika. Wat ons ook al aan terme daarvoor gebruik het, die feit - die ware werklikheid wat God gee, bly staan: Ons in Suid-Afrika is 'n samelewing in etniese meervoudigheid met die etnies uitkenbare dele of komponente wat dikwels in taal en kultuur, in godsdiens en sedes diep van mekaar geskei is.

Daar is 'n plurale, veelvolkige, veeltalige Suid-Afrikaanse gemeenskap. Maar daar is nie Suid-Afrikaners nie. Daarom pas die patroon van „majority-rule" wat wesenlik ondemokraties is, nie 
op ons samelewing nie en móét ons die werklik demokratiese bestel soek in ooreenkoms, saambesluit, saampraat en praat tot instemming bereik is. Dit word ook ,konsensus" genoem. Want elkeen wat dink, kan tog sien dat daar in Suider-Afrika baie onafhanklike state kom wat ekonomies interafhanklik is. Die presiese patroon van die politieke struktuur kan niemand nou gee nie - dit moet die state in die toekoms met mekaar doen in konsensus en sonder heerskappy van een oor ander of almal, soos sommige Zoeloes wil en sommige witmense ook. Vir Suider-Afrika is dit 'n saak om gereël te word soos Wes-Europa dit moet doen en die Arabiese state ook. (Daarom het ek in 'n preek die ,Vorster-Rabin pakt" bevraagteken - bloot prakties polities gesien, waarom nie liewer met die Arabiese state saam nie? Ons is tog in Afrika?).

\section{Suid-Afrika wat agter bly}

Wat dan van die ou Suid-Afrika uiteindelik agterbly, is die plurale gemeenskap van Witmense, Kleurlinge, Asiërs en die groeiende uiteindelike onbetwiste meerderheid, die Swartes in stedelike gebiede. Dit is reeds meer as 'n voorneme om die wittes, gekleurdes en Asiërs in een staatstruktuur bymekaar te kry en die swartes in eie plaaslike sake volle seggenskap te gee, maar wat word dit? Stadstate? Die stertjie wat die hond van die swart state swaai of die koevoet wat die wit-kleurling-Asiër gemeenskap omgooi? Dis hoog tyd dat die regering of iemand anders sê wat die bedoeling met die staat- en stadstrukture is sodat ons daaroor 'n mening uit kan spreek. Nou is dit raaiwerk. Maar ek mis die idee, ideaal, beginsel in baie wat ons staatsmanne sê, dikwels teenstrydig sê. En ek huiwer as 'n minister van homself sê: $E k$ is 'n pragmatis!

Ons dink in hierdie saak - m.i. Skriftuurlik reg - aan veelvolkigheid, etniesietyd en ons identifiseer die volke van ons land by name. Maar benewens baie vrae hierin staan vir my twee uit: Wie en wat is die Kleurlinge? Wie en wat is die Afrikaners? Die laaste vraag eerste: Die Afrikaanse volk, so glo ek, is hier geroep en gemaak deur die Here. Ons het sterk identiteitskenmerke: ons godsdiens, taal, kultuur en land. Vir die volksbepalende sake het ons voorouers en ons gestry en stry ons nog. Dit is noodsaaklik want dis waar wat Fritz Steyn en F. A. van Jaarsveld sê: Afrikaans verloor vinnig veld t.o.v. Engels, dit word 'n vertaalde Engels, maar ek is nie pessimisties soos hulle nie; dis ook waar wat W. de Klerk sê: Ons kultuur verslap en veragter en sink in, en ek dink positief soos hy: bou dit met alle mag weer op want dis bepalend vir ons volkswees; en in ons godsdiens vervlak ons, sê ek en baie kerkmense sê dit ook.

\section{Waar ek dit teen het}

Maar dan het ek dit teen Die Transvaler wat met alle geweld die S.A. Akademie vir Letterkunde, Kuns en Wetenskap vir almal oop wil gooi en volhou om dit as Afrikaner-identiteit te rysmier; en ek het dit teen Hoofstad e.a. wat die voortbestaan van die Afrikaanse Handelsinstituut bevraagteken; en teen die mense wat die 
Gelofte en Geloftefees wil verkerklik en sy Afrikaner-identiteit daardeur wil verbreek; en ek het dit teen party van die NGK wat die „,oorkoepelende-sinode" gelyk skakel met die beëindiging van die Afrikaanse volk (hieroor later meer); en teen die ,koinonia” mense en die New Evangelicals wat die bevolking van S.A. sien as 'n ,,integrated society" of ,community"; en teen die New Evangelicals wat die nuwe mensheid in Christus nie wil ken in sy ryk variasie van volke en tale en nasies nie, maar as 'n grys uniformiteit wat ook die patroon moet wees van die Suid-Afrikaanse gemeenskap; en teen die CRC en die GKN wat die bestaan en bestaansreg van die Afrikaanse volk nie wil erken nie; en teen universiteitsmense en studenteraadsvoorsitters wat die Afrikaanse Universiteite „oop" universiteite wil maak, ook die PU vir CHO; en teen die Afrikaanse sportlui wat sportklubs 'n allegaartjie maak en teen die heidense kabaal in Pretoria op die Caledoniese terrein as die swartes dit oorstroom en wesenlik 'n gevaar geword het vir die omgewing; en teen ons manne wat die Afrikaner nog nie ken as 'n volk van Afrika nie maar ons alewig vas wil haak aan Wes-Europa en veral Amerika en die patroon van daardie lande se huishouding oor ons land en volk wil lê en ons land daarvolgens by wil knip; veral dié van die VSA met sy swart-minderheidsregering of sy Trilatteral Commission of Sionism wat die wêreld wil regeer soos die kommuniste of eintlik saam met hulle - die arme wittes van die VSA, die land wat eintlik deur Calviniste gemaak is maar nou lewendlam is onder Joodse en dollar kommunikasiemedia soos 'n spinnekop lam is na die perdeby se steek maar lewe het waarin die by sy larwes kweek.

\section{Behoud van identiteit}

Maar ek verveel $\mathrm{u}$ met my ante's. Wat ek wil tuis bring is die noodsaaklikheid van die behoud van ons Afrikaner identiteit en van ander volksentiteite en -identiteit want dit is die behoud, as God dit wil, van ons land en beskawing. En dan moet ons oor die Kleurlinge klarigheid kry voor dit te laat is. Hulle wil reeds, doelbewus en uit reaksie, hulle taal en kultuur, wat ons taal en kultuur is, verruil vir Engels, soos die swartes Engels verkies bo Afrikaans. Ons het daar baie skuld aan. Ek sou hier gewoon en eerlik en Christelik sê: Daar is wit Afrikaners en bruin Afrikaners en saam is ons die Afrikaanse volk met ons taal en kultuur en land en godsdiens identiteit - hoe gouer hoe beter. Daar is in so 'n vitale Afrikaanse volk oorgenoeg innerlike en natuurlike $\mathrm{krag}$ om in belange en gemeenskapsektore van welke aard ook al te integreer waar nodig en te segregeer waar nodig - sonder wetgewing.

\section{Ons sonde met wette}

Juis met wette het ons gesondig en met regeringsbesluite en regulasies sonder dikwels die wil of medewete van die onderdane. Begryp my goed: my uitgangspunt bly my belydenis in art. 36 NGB: "Ek glo dat ons goeie God vanweë die verdorwenheid van die menslike geslag, konings, vorste en owerhede aangestel het; 
want dit is sy wil dat die wêreld geregeer moet word deur middel van wette en regerings, sodat die losbandigheid van die mense in bedwang gehou kan word en alles onder die mense ordelik kan verloop". Maar dan is ontug ontug en nie net as dit oor rassiale grense heen gepleeg word nie; en dan het God aan die owerheid regte en gesag en mag gegee, en nie die onderdane nie, en Gód het aan die onderdane regte en pligte gegee - die een moet die reg van die ander respekteer; en dan het God die ouers regte en pligte oor die opvoeding en onderwys van hulle kinders gegee en die owerheid mag dit nie vervreem nie; en dan het 'n huwelikspaar én hulle familie én die kerk én die samelewing én die owerheid belang en seggenskap, elk op sy terrein, by die voorgenome huwelik en moet almal waarsku teen die ellendes van rasgemengde huwelike maar die owerheid mag die belange van ander nie vervreem nie; en dan moet die owerheid in gevaarvolle tyd die wet en orde en vrede handhaaf in geregtigheid, ook met harde hand, en die burgers en die land verdedig teen die vyand wat ons wil vernietig, en die burgers moet gehoorsaam wees. En as dit dan noodsaaklik is dat iemand aangehou word - voorlopig, sonder aanklag en verhoor - vir die veiligheid van die staat, moet dit gebeur in reg en geregtigheid, maar dit behoort nie lank te duur nie en moet op ' $n$ regsaak en regspraak uitloop. Let wel in Holland, Engeland, Amerika en Wes-Duitsland kan só ook aangehou word vir korter duur - om nie te praat van die mensonterende en verontregtende praktyke van die Sowjets en party Afrika-diktators nie.

\section{Gevaar van institusionalisme en - ismes}

Ek kom terug by dit waarmee ek begin het. Algaande het ek, wetenskaplik onverantwoord maar opsetlik omdat dit my pas, danig aangegaan met die struktuurbegrip, al begryp ek dit nie. Veroorloof my dit nog een maal as ek oor die kerk praat. Ons, veral ons omdat ons klein is en alles ingooi om die leer suiwer te hou en na God se Woord te luister, moet oppas vir institusionalisme en strukturalisme en konfessionalisme en independentisme. Ons moet uit 'n soort verstarde selftevredenheid uitkom en dinamies deelneem, soos weleer, aan alle sektore van die lewe in waaragtige kerk-wees. Ons moet meer kragtens kerkverband as kerke gesamentlik optree op die politieke en staatkundige terrein om die regering en die samelewing te konfronteer met die evangelie. En ons moet meer en beter praat met ander kerke oor die waarheid van God se Woord en saam met hulle vir die waarheid staan in politiek en sosiale kwessies; daarvoor moet ons ons kerklike betrekkings duidelik formuleer, goeie administratiewe en uitvoerende masjinerie skep vir die behartiging van die betrekkinge en desnoods ' $n$ predikant beroep vir die werk. Want dis nie net ons wat sien wat in die wêreld gebeur nie. Baie gelowiges en kerke sien dit en hulle soek mekaar in die bitter stryd teen die vyand; ons moet hulle vind en onsself laat vind, met ander die geledere probeer sluit op grond van die Waarhcid van God in Christus. Vir ons beskamend, het baie reeds in die stroom gespring en hulle staan in die branding. Ons 
het nie niks gedoen nie, maar ons skiet te kort. Die idee ,veelvolkigheid" is waarskynlik van ons afkomstig; vir sover ek weet het net één Afrikaanse kerk - 'n kerkraad van 'n Gereformeerde Kerk - ernstig beswaar gemaak toe wetgewing i.s. eredienste - rasgemengde eredienste - op die Wetboek geplaas is. Ek noem net die twee, daar is meer maar te min. Wat verkeerd is in ons politieke en sosiale konstruksies, moet ons aan die kaak stel en daarteen optrek - ons het, Goddank, die geleentheid in ons land en manne aan bewind wat luister na die evangelie.

\section{Barmhartigheidsdiens}

Ons identiteit is dat ons in ons lewe die beeld van Christus moet vertoon, veral in die barmhartigheid. Want, let op, let goed op, barmhartigheid is die toets wanneer die Seun van die Mens in sy heerlikheid kom en op die troon van die geregtigheid sal sit. Hy sal dan die nasies van mekaar skei soos mens skape van bokke skei - skape regs en bokke links. En aan die skape sal Hy sê: Kom, julle geseëndes van My Vader, beërf die koninkryk! En Hy sal praat oor honger en dors, oor vreemdelingskap en naaktheid, oor siekte en gevangenskap en oor ons barmhartigheid aan Hom bewys maar veral aan mekaar en aan alle mense en selfs aan die geringstes onder die kinders van God.

Ons het 'n gulde geleentheid om op die welsynsterrein baie te doen. Deur geld te leen by ons kerkfondse en by die Geref. Kerk, Pretoria, teen behoorlike rentekoers, of om dit as sekuriteit te gee, kan ons al ons welsynsorganisasies vrykoop van regeringsgeld en sosialistiese maatreëls en neigings en al die eiendomme transporteer op die naam van die trustees van die Geref. Kerk in Suid-Afrika. Dán kan ons mense help en versorg soos min ander dit kan doen, want die subsidies kry ons dan van die diakonieë, van gelowiges se barmhartigheidsdiens. Dán kan ons barmhartig en volmaak wees en kan ons liefde betoon aan baie mense van baie volke in ons land en daarbuite. Daar is nood en oorlog; ons getalle word minder - nog 25 jaar gee party geleerdes die Afrikaanse volk wat nie meer kinders kry nie (dink aan maarskalk Petain se woorde in die oorlog toe hy Frankryk se oorgawe onderteken het). En as daar nood is moet die kerk inisieer en doen. Laat ons dit doen, nou doen!

\section{Gereformeerde kerke in eenheid}

En laat ons uit die lig van God se Woord ons kerk se naam verander voordat die staatkundige en sosiale struktuurveranderings ons onverhoeds betrap en ons dwing om verkeerde kerkbegrippe na te volg. Ons Gereformeerde kerke is mos een; laat ons een wees in ons naam: Die Gereformeerde Kerke van Suider-Afrika. Ons behou die verskeidenheid in taal, kultuur, volk - en laat ons nie op sleeptou neem deur sommige broeders van die NGK se vrees en verkeerde kerkbegrip wat van die sinode, ook oorkoepelende sinode, die kerk maak en van kerk sinode en, soms, Afrikaanse volk. 
Maar genoeg. Dis laat op God se horlosie en Christus roep ons, sy leërmagte, op. Die struktuurpatroon van die ryk van die duisternis word duidelik: een magtige, valse, sogenaamde gelykheid en eenheid in één wêreldorde onder een wêreldregering. Die VSA en die USR en Sionisme, die WRK en die VVO werk almal daarin saam. Andy Young - 'n kollega van die ,kleed” — sê ons moenie bang wees vir die kommuniste nie, nie emosiioneel dink nie, want hulle stabiliseer! Dit is die balans van die dollar - en die hamer en sekel, die Trilatteral Commission en die Kremlin. Dit kom, ons kan dit nie keer nie, en dis netnou hier.

Die utopia kom, 'n mensgemaakte beter wêreld, beter woonplek vir getalle wat onstuitbaar groei. 'n Wêreld van mensevrede en mensaanbidding. Dit kom - en God sal dit verbrand!

Want sy koninkryk is hier en kom ook. Dit is die ware, nuwe, die ware vrede, die ware en ewige glorie van God.

Gelewer voor GTV-jaarvergadering te Pretoria-Oos, 13 Junie 1978. 